\title{
A Systematic Literature Review of Students as Partners in Higher Education
}

\author{
Lucy Mercer-Mapstone ${ }^{a}$, Sam Lucie Dvorakova ${ }^{a}$, Kelly E Matthewsa, Sophia Abbot ${ }^{b}$, Breagh \\ Cheng ${ }^{c}$, Peter Felten ${ }^{d}$, Kris Knorrc, Elizabeth Marquis ${ }^{c}$, Rafaella Shammas ${ }^{c}$, Kelly Swaim ${ }^{d}$ \\ a Institute for Teaching and Learning Innovation, University of Queensland, St Lucia, 4072, \\ Brisbane, Queensland, Australia \\ ${ }^{b}$ Collaborative for Learning and Teaching, Trinity University, San Antonio, Texas, United States \\ of America \\ 'MacPherson Institute, McMaster University, Hamilton, Ontario, Canada \\ d Center for Engaged Learning, Elon University, Elon, North Carolina, United States of America
}

Contact: I.mercermapstone@uq.edu.au

\section{ABSTRACT}

"Students as Partners" (SaP) in higher education re-envisions students and staff as active collaborators in teaching and learning. Understanding what research on partnership communicates across the literature is timely and relevant as more staff and students come to embrace SaP. Through a systematic literature review of empirical research, we explored the question: How are SaP practices in higher education presented in the academic literature? Trends across results provide insights into four themes: the importance of reciprocity in partnership; the need to make space in the literature for sharing the (equal) realities of partnership; a focus on partnership activities that are small scale, at the undergraduate level, extracurricular, and focused on teaching and learning enhancement; and the need to move toward inclusive, partnered learning communities in higher education. We highlight nine implications for future research and practice.

KEYWORDS

students as partners, student-staff partnership, higher education, systematic literature review

\section{CC-BY Licence 4.0 This is an Open Access article distributed under the terms of the Creative Commons - Attribution License 4.0 International (https://creativecommons.org/licenses/by/4.0/), which permits unrestricted use, distribution, and reproduction in any medium, provided the original work is properly attributed.}


"Students as Partners" (SaP) embraces students and staff (including academic/faculty and professional staff) working together on teaching and learning in higher education. Partnership is a "reciprocal process through which all participants have the opportunity to contribute equally, although not necessarily in the same ways, to curricular or pedagogical conceptualization, decision-making, implementation, investigation, or analysis" (Cook-Sather, Bovill, \& Felten 2014, pp. 6-7). Healey, Flint, and Harrington (2014) describe SaP as "a relationship in which all involved-students, academics, professional services staff, senior managers, students' unions, and so on-are actively engaged in and stand to gain from the process of learning and working together" (p. 12). Acknowledging that SaP is inherently process-orientated rather than outcomes-driven, Matthews (2016) distinguishes between student engagement, which emphasizes what students do at university, and SaP, which is focused on what students and staff do together to further common educational goals. SaP is enacted within "an ethic of reciprocity" (Cook-Sather \& Felten, 2017) that is underpinned by partnership principles of respect, reciprocity, and shared responsibility in learning and teaching (Cook-Sather et al., 2014).

While SaP can encompass a range of practices and pedagogies, the common thread is a re-positioning of the roles of students and staff in the learning endeavor, grounded in a valuesbased ethos. Partnerships can happen within or outside of curricula; between individuals, small groups, or large cohorts; in courses (also known as modules or units); or across entire programs of study. To make sense of the plethora of partnership practices, Healey et al. (2014) propose a model (Figure 1) to highlight where students and staff may engage as partners to further learning, teaching and research, and teaching enhancement efforts across four overlapping categories: subject-based research and inquiry; scholarship of teaching and learning (SoTL); curriculum design and pedagogic consultancy; and learning, teaching, and assessment. This model positions students and staff as co-teachers, co-inquirers, curriculum co-creators, and colearners across all facets of the educational enterprise.

The beneficial outcomes of engaging in partnership are emerging in published literature. Cook-Sather et al. (2014) report positive learning impacts for students, while Bovill et al. (2010) and Werder, Thibou, and Kaufer (2012) describe an increased sense of leadership in, responsibility for, and motivation around the learning process for students and staff engaging in partnership. Scholars report a transformed sense of self and self-awareness for both students and staff (Werder \& Otis, 2010; Bovill, Cook-Sather, \& Felten, 2011; Cook-Sather et al., 2014; Cook-Sather \& Abbot, 2016) alongside the development of more inclusive teaching practices (Cook-Sather \& Agu, 2013). Bovill, Cook-Sather, Felten, Millard, \& Moore-Cherry (2016) discuss the challenges that exist in SaP work in terms of three broad categories. First, the customs and culture of higher education often make it difficult for both students and staff to take on new roles and perspectives. Second, institutional structures, practices, and norms typically present practical barriers to the kinds of collaboration and shared power involved in partnerships. Third, establishing an inclusive approach to partnership can be challenging; yet, inattention to this issue risks leaving out already marginalized students and staff. 


\section{Figure 1. Model depicting ways of engaging students as partners in higher education}

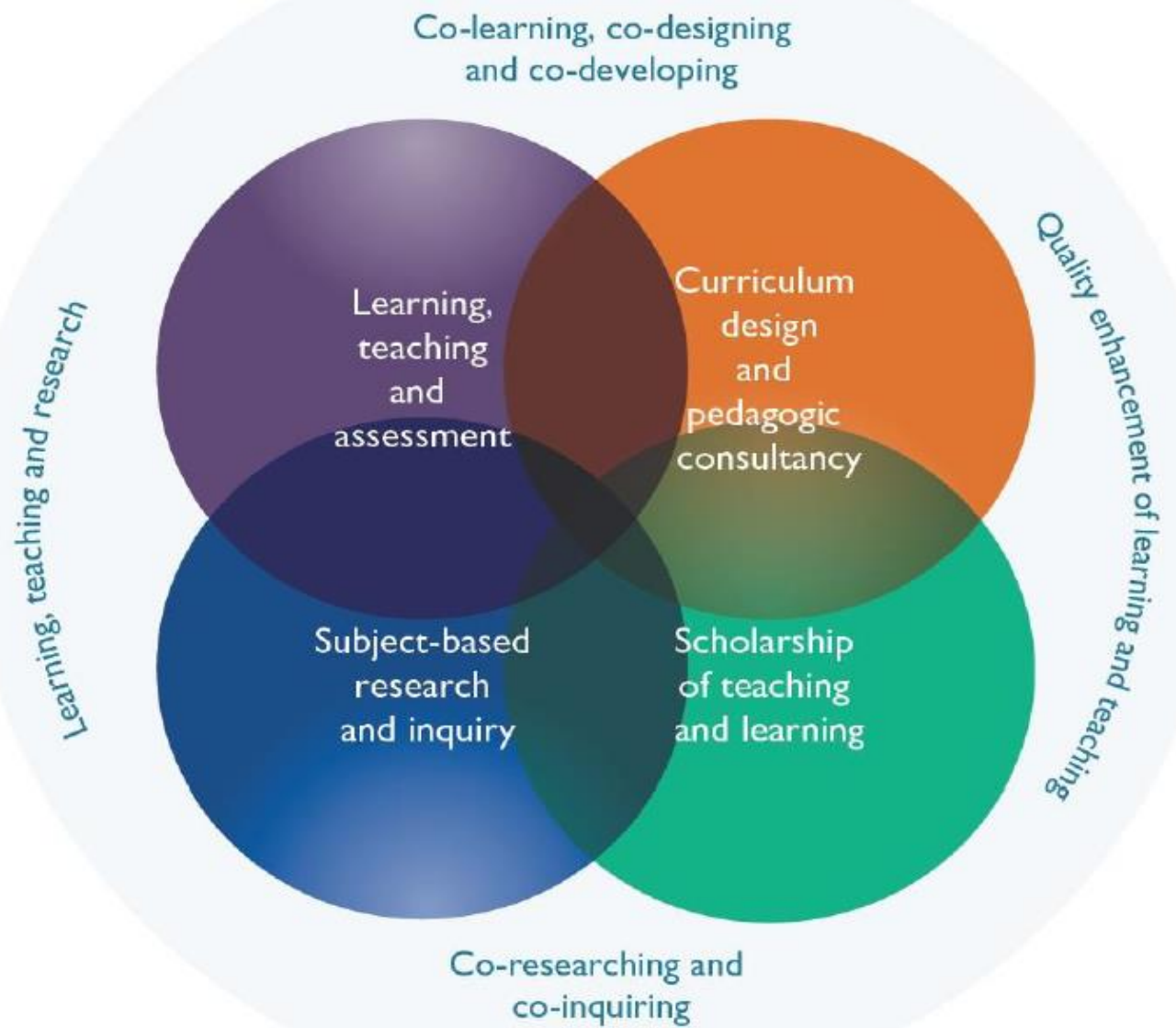

Source: From Engagement Through Partnership: Students as Partners in Learning and Teaching in Higher Education, by M. Healey, A. Flint, and K. Harrington, 2014, The Higher Education Academy, p. 24. Copyright 2014 by the Higher Education Academy. Reprinted with permission.

Previously published research offers early insights into a range of SaP practices, and into the outcomes and pragmatic realities of engaging in such work. With more staff and students coming to embrace SaP and translating the principles into practices that suit their local contexts, understanding what research on partnership communicates across the literature through a scholarly analysis of publications is both timely and relevant.

\section{CONTRIBUTION OF STUDY AND RESEARCH QUESTIONS}

Research and practice in the partnership arena is gaining significant momentum as SaP gains prominence internationally (Bovill \& Felten, 2016; Cook-Sather, 2014). Matthews, CookSather, \& Healey (in press) point to such prominence through the rise of special issues of 
established journals, citing volume 21, issue 2 of the International Journal for Academic Development and volume 23, issue 5 of Mentoring \& Tutoring: Partnership in Learning, as well as featured pieces in newer journals, including pieces in volume 1, issue 1 of Student Engagement in Higher Education Journal and in volume 4, issue 2 of Teaching, Learning and Inquiry. Alongside these noteworthy publications, they also cite a new journal dedicated to partnership research (International Journal for Students as Partners), and international teaching and learning workshops focused on partnership practices (e.g., the International Summer Institute on Students as Partners, hosted by McMaster University, Canada). Our initial intention in conducting this literature review was to learn more about students as partners by reading this breadth of often disparate literature in an organized manner. As we began to discuss our approach, we realized we could make a broader contribution for those who, like us, were grappling with the realities of translating theory and research into practice. Thus, the overarching question guiding our literature review was: How are "students as partners" practices in higher education presented in the academic literature? In this article, we consider the following sub-questions:

1. Who authors SaP work, from what disciplines, and in what contexts?

2. In what areas are students and staff engaged in partnership?

3. Who partners in SaP initiatives, at what scale, and in what relation to the curriculum?

4. What and how often are positive and negative outcomes reported for students and staff engaged in SaP initiatives?

Our aim is to explore the published literature in the emerging SaP field and contribute an evidential baseline that might guide future directions for research and practice.

\section{METHODS AND ANALYSIS}

We conducted a systematic literature review inspired by the works of Amundsen and Wilson (2012) and Matthews et al. (2013) and informed by Kennedy (2007). This involved "defining the body of literature"; reviewing the literature based on an analytic framework; and analyzing and interpreting results.

\section{Defining the body of literature: inclusion and exclusion criteria}

As SaP encompasses a diverse range of existing practices and terms in higher education, searching standard databases was not feasible in returning a comprehensive set of articles. Our body of literature was sourced from combining two "expert bibliographies" from active researchers (Alison Cook-Sather and Mick Healey, see for example, Healey (2016)), both highly cited and recognized experts in the SaP field (as evidenced by keynotes, consultations, and invited talks) who have created reference lists of relevant works. We asked these two experts and a third, Peter Felten, to confirm the comprehensiveness of the compiled database. Given our focus on works situated explicitly within the language of SaP, we then checked the database by searching Google Scholar using the term "students as partners." given our focus on works situated explicitly within the language of SaP. This process resulted in an initial database of 386 
published works (peer-reviewed articles, reflective essays, book chapters, research reports, conference papers, and case studies) from 1968 to 2016.

Kennedy (2007) suggests that defining the body of literature for any literature review inevitably includes and excludes work, and those conducting such reviews need to be clear about what criteria were employed. Inclusion criteria for works to be analyzed in our study were: (1) written in English; (2) situated in higher education; (3) published between 2011-2015 (inclusive); (4) self-identified by the authors as "students as partners" or similar terms; (5) based in an empirical study and grounded in the literature; and (6) peer-reviewed. These criteria excluded purely theoretical work, articles testing a data collection instrument, works not explicitly situated as SaP, and works that were not situated within the citation of other literature.

The process for refining the article database was twofold. First, works other than conference papers, journal articles, book chapters, and professional society research reports were removed along with works not published between 2011 and 2015 . This resulted in a database of 130 items. Second, researchers read all remaining works and further culled those that did not meet the inclusion criteria. This resulted in 65 works being analyzed. A bibliography of these analyzed articles is available at http://espace.library.uq.edu.au/view/UQ:449124.

\section{Review team}

The analysis was conducted in partnership, involving 12 students and 8 staff, a total of 20 researchers, from 6 different higher education institutions and 4 countries: Australia, Canada, the UK, and the USA. Researchers came from a range of disciplines (e.g., biosciences, communications, education, geography, history, and physical sciences).

\section{CONDUCTING THE ANALYSIS}

Our analysis approach followed that of Matthews et al. (2013) involving three rounds of piloting an online survey-style analysis instrument, followed by partnered analysis. First, three phases of testing the online instrument were conducted, which involved researchers working within "country teams" (i.e., teams comprised of members from the same country) that read, discussed, and analyzed the same articles and entered results into the online survey.

Differences in interpretation were identified and discussed, and the analysis instrument was revised accordingly. This iterative process was essential for revealing implicit differences in how the researchers conceptualized and classified SaP works.

To conduct the final analysis, each article was read and analyzed by two researchers independently. These researchers then consulted each other regarding the analysis and came to agreement on the classification of the article and the responses to be entered in the analysis instrument. Where researchers could not agree, they indicated the need for a third researcher's consultation. Once consensus was reached about an article, the data were entered into the analysis instrument so that information was captured in a standardized format.

\section{Framework for analysis}

The purpose of our analytical framework was to systematically capture data from each article guided by our pre-determined research questions whilst also reducing variability in the

Mercer-Mapstone, L., Dvorakova, L.S., Matthews, K.E., Abbot, S., Cheng, B., Felten, P., Knorr, K., Marquis, E., Shammas, R., \& Swaim, K. (2017) A Systematic Literature Review of Students as Partners in Higher Education. International Journal for Students as Partners 1 (1) 
interpretation of the published research. Two papers (Amundsen \& Wilson, 2012; Matthews et al., 2013) were heavily drawn on to develop the analytical framework, which aimed to interrogate individual articles in a rigorous and repeatable manner, shaped by certain questions. Our analysis instrument systematically guided the collection of data about each article according to the sections and categories shown in Table 1. All categories or answers in the analysis instrument sections were drawn from our existing collective knowledge of the SaP literature prior to data collection. When new categories arose in the open response "Other" option for each question, we compiled these data into new categories; results are reported below.

\section{Table 1: Sections and categories from the analysis instrument used to systematically review and collect data from analyzed articles}

\section{Analysis Instrument Section Categories/Options Within that Section}

\begin{tabular}{|c|c|}
\hline Demographic information & journal, year, country of first author \\
\hline Institutional context & $\begin{array}{l}\text { single university, multiple universities in the same country, multiple universities } \\
\text { in different countries, other (specify) }\end{array}$ \\
\hline Authorship & staff or students, staff or student first author, other (specify) \\
\hline Disciplinary context & discipline, collaboration of disciplines, other (specify) \\
\hline $\begin{array}{l}\text { Student involvement in } \\
\text { reported initiative }\end{array}$ & number, undergraduate or post-graduate, other (specify) \\
\hline $\begin{array}{l}\text { Students in reported } \\
\text { initiative partnering with }\end{array}$ & $\begin{array}{l}\text { other students, academic teaching staff, professional teaching support staff, } \\
\text { other (specify) }\end{array}$ \\
\hline $\begin{array}{l}\text { Curricular location of } \\
\text { reported initiative }\end{array}$ & $\begin{array}{l}\text { within graded curriculum (if so, single subject or across several subjects), extra- } \\
\text { curricular, other (specify) }\end{array}$ \\
\hline $\begin{array}{l}\text { Payment for student } \\
\text { participation in reported } \\
\text { initiative }\end{array}$ & Paid (incl. scholarship or stipend), not paid, unclear, other (specify) \\
\hline $\begin{array}{l}\text { Positive and negative } \\
\text { outcomes of reported } \\
\text { initiative for students }\end{array}$ & $\begin{array}{l}\text { engagement, sense of belonging, confidence, learning gains, trust with staff, shift } \\
\text { in power relationships, engagement of under-represented cohorts, insight into } \\
\text { staff's experiences, other (specify) }\end{array}$ \\
\hline $\begin{array}{l}\text { Positive and negative } \\
\text { outcomes of reported } \\
\text { initiative for staff }\end{array}$ & $\begin{array}{l}\text { changed teaching practices, new curriculum resources, trust with students, shift } \\
\text { in power relationships, motivation, insight into students' experiences, other } \\
\text { (specify) }\end{array}$ \\
\hline $\begin{array}{l}\text { Fit of reported initiative into } \\
\text { existing models }\end{array}$ & Healey et al. (2014) “Engaging Students as Partners" model \\
\hline
\end{tabular}

\section{RESULTS}

A total of 65 scholarly articles, book chapters, and research reports drawn from 28 research journals and nine books formed the analyzed dataset used to explore our broad 
question: How are "students as partners" practices in higher education presented in the academic literature? Below, we report results from the four sub-questions that are the focus of this article.

\section{Demographics of publishing on SaP in higher education}

Eighty-nine percent of the analyzed papers $(n=58)$ were written by staff first authors, while $5 \%(n=3)$ had undergraduate student first authors, and $2 \%(n=1)$ were written by postgraduate first authors. The remaining were not specified. Overall, $99 \%(n=64)$ of articles included a staff member as a co-author, with the single outlying paper not classified due to lack of in-text detail. Twenty-one papers (32\%) also included a student (17 of these being undergraduates) as a co-author.

Partnership initiatives were most commonly conducted within a single university $(80 \%$, $n=52)$, with $20 \%(n=13)$ conducted in multiple institutions. Partnerships were most frequently implemented at the institutional level (outside of a specific discipline, for example, at the institutional level, $40 \%, n=26$ ) with four classed as multidisciplinary collaborations among disciplines (5\%). Summary statistics describing those initiatives conducted within a disciplinary context are presented in Table 2.

Table 2: Prevalence of different disciplinary contexts of partnerships

\begin{tabular}{llc}
\hline Disciplinary Context & Percentage & Number \\
\hline Outside specific discipline (e.g. at the institutional level) & 40 & 26 \\
\hline Health, medical, and behavioral sciences (including psychology) & 22 & 14 \\
\hline $\begin{array}{l}\text { Science, engineering, technology, and mathematics (including architecture, } \\
\text { computer science, information technology) }\end{array}$ & 17 & 11 \\
\hline Humanities, arts, and liberal arts & 14 & 9 \\
\hline Social sciences & 12 & 8 \\
\hline Business, economics, law, and marketing & 8 & 5 \\
\hline Multidisciplinary collaboration & 6 & 4 \\
\hline
\end{tabular}

Note: Some papers were situated in more than one disciplinary context and were thus selected in multiple categories. Therefore, the sum total of numbers here will be greater than the sample size. Percentages were calculated as portions of the whole sample, so will not add up to $100 \%$.

\section{Areas for engaging SaP in higher education}

Analyzed papers were categorized according to which quadrant of the Healey et al. (2014, Figure 1) "Engaging Students as Partners" model the partnership initiative best "fit" into. Each number reported here represents the total number of papers identified as belonging to a particular Healey category individually or in combination (overlapping) with other categories: $54 \%(n=35)$ categorized as "curriculum design and pedagogic consultancy"; $31 \%(n=20)$ as "SoTL"; $22 \%(n=14)$ as "learning, teaching and assessment"; and $12 \%(n=8)$ as "subject-based 
research and inquiry." Three papers (5\%) did not fit into any of the quadrants. Some papers (20\%, $n=13$ ) described initiatives that were categorized as "overlapping" - fitting into more than one quadrant of the model. Graphical representation of these categorizations (singular and overlapping) is shown in Figure 2.

Figure 2. Partnership initiatives according to categories of partnership

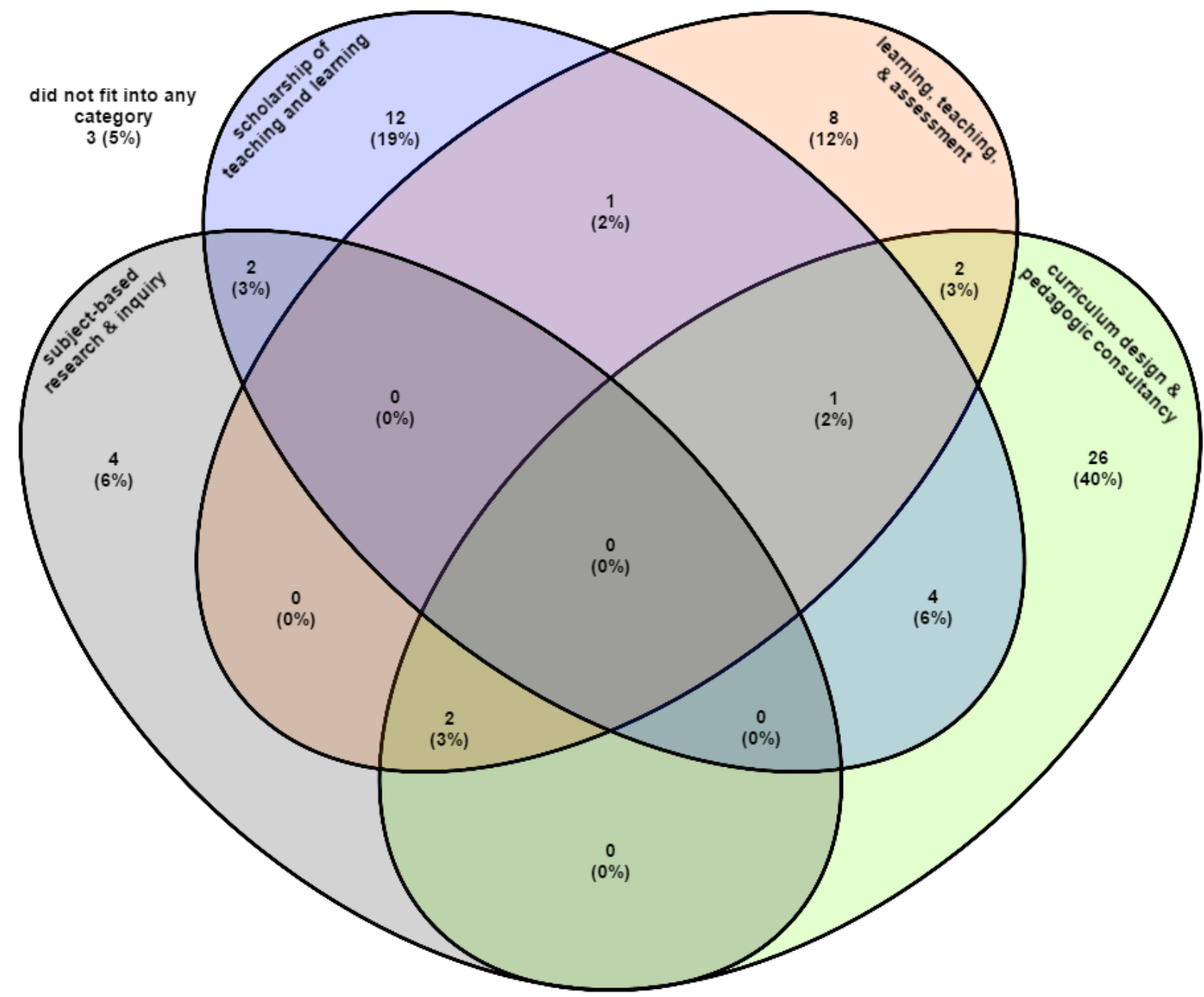

Individual and overlapping categorizations of partnership initiatives $(\mathrm{N}=65)$ within the four quadrants of the Healey, Flint, \& Harrington (2014) “Engaging Students as Partners" model.

Note: 62 papers were assigned to at least one of the categories; three papers did not fit into any category.

\section{Partnering in higher education: Partners, scale, and curricular location}

Described partnership initiatives were most commonly small scale including 1-5 students $(25 \%, n=16)$. Very few large scale initiatives were recorded (Figure 3$)$. A large portion of the articles analyzed $(26 \%, n=17)$ did not explicitly specify the number of student partners involved in the initiative. 
Figure 3. Number of students involved in partnership initiatives described as reported by authors of analyzed papers $(n=65)$

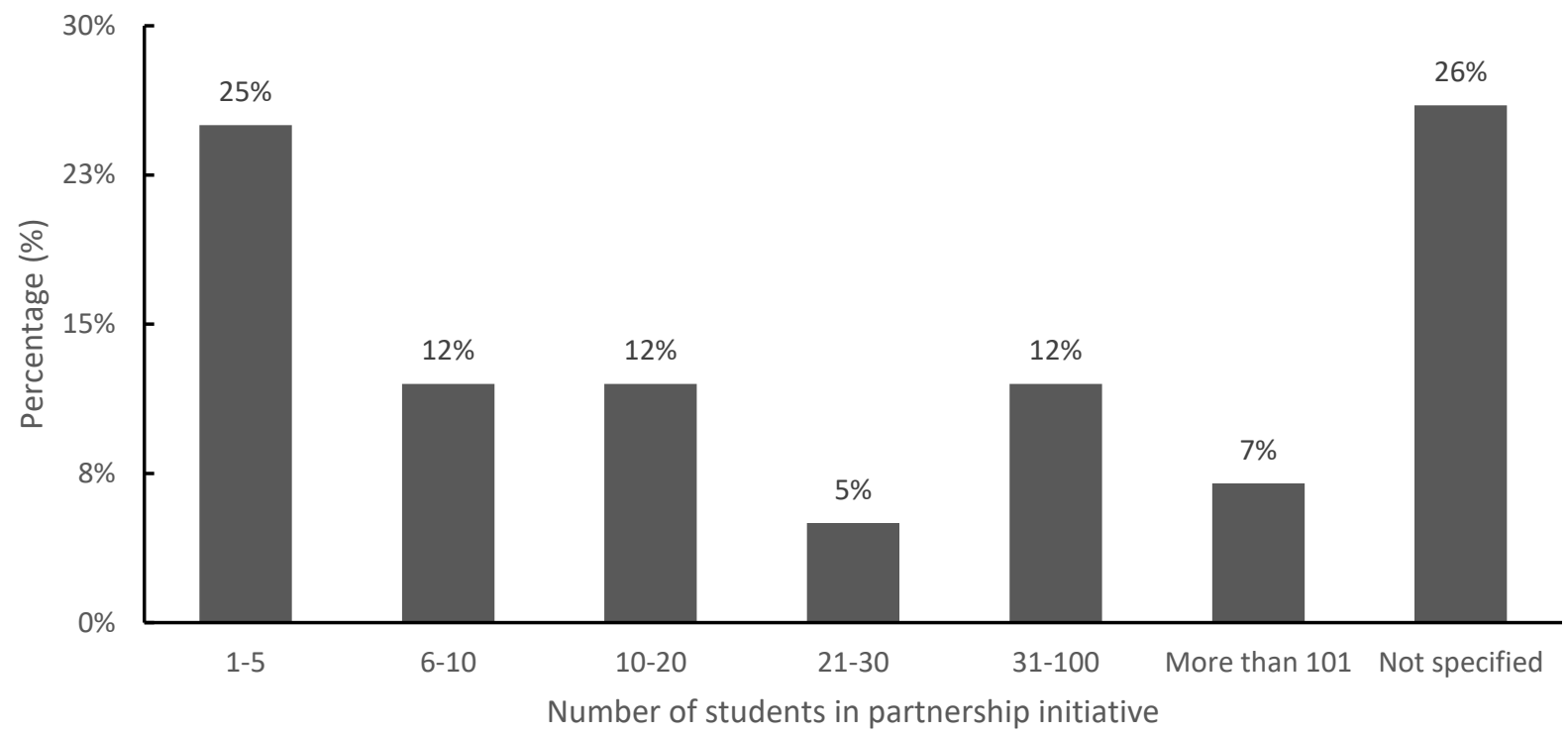

Students of diverse academic levels were involved in partnership. Undergraduate students were most frequently involved $(74 \%, n=48)$, with postgraduates being involved less often $(20 \%, n=13)$. Finally, $18 \%(n=12)$ of articles did not specify the level of students involved.

Figure 4. Visual representation of who students partnered with during their partnership initiatives as reported by authors of papers analyzed $(n=65)$

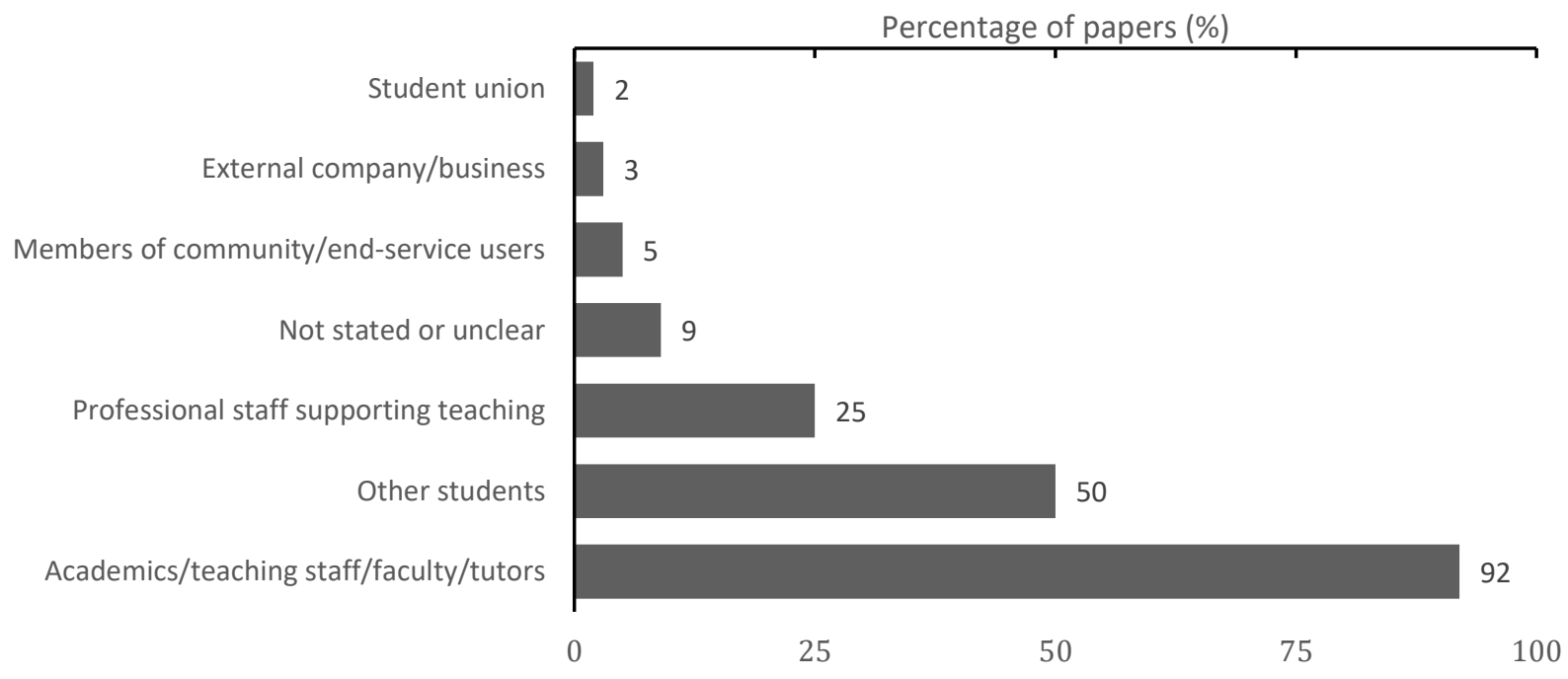


The majority of initiatives saw students partnering with academic/teaching staff/faculty/tutors (92\%, n=60) and/or other students (51\%, n=33). Student-student partnership presents a diverse set of activities in higher education. Such partnerships in the analyzed articles were framed explicitly by authors as partnership activities that extended beyond, for example, group work. An example of one of the student-student partnerships occurring alongside of staff-student partnership in our dataset is in Pedersen, Lymburner, Ali \& Coburn (2013), which detailed the organization of an undergraduate psychology conference where students partnered with each other on specific tasks and during the general organization, as well as with members of staff, to achieve their goal of creating a conference. Further details about who was involved in the reported partnership initiatives are presented in Figure 4.

The majority of partnerships took place outside of the graded curriculum as extracurricular (non-graded) activities $(59 \%, n=38)$. Partnerships were also reported in a single unit (also called course, subject; $12 \%, n=8$ ), as well as in multiple units that involved students being graded $(12 \%, n=8)$. The remaining 11 papers did not offer sufficient detail for categorization. We recorded that $35 \%(n=23)$ of partnership initiatives paid students (this includes payment via scholarship or stipend), whilst $26 \%(n=17)$ did not. Many publications did not explicitly state whether students were paid $(37 \%, n=24)$.

\section{Positive outcomes of partnership for students and staff}

The majority of papers reported positive outcomes for students ( $92 \%, n=60)$. The full list of positive outcomes for students is shown in Table 3 with frequencies. "Other" positive outcomes for students included increased quality of teaching, financial benefits, enhanced student-staff communications in tutorials, and enhanced creativity for students. Many papers $(79 \%, n=51)$ also reported positive outcomes for staff. The full list of positive outcomes for staff is shown in Table 4 with frequencies. "Other" positive staff outcomes included staff saving time through partnership, enhanced staff experience in research, and freeing up staff to engage more students.

\section{Negative outcomes of partnership for students and staff}

Negative outcomes were less frequently reported for students with $74 \%(n=48)$ of papers not reporting any. For those papers that did report negative student outcomes, details are shown in Table 5. Very few negative outcomes were reported for staff with $85 \%(n=55)$ of papers not stating any. The most prevalent negative outcomes reported were that partnerships reinforced pre-existing power inequalities $(5 \%, n=3)$, gave feelings of vulnerability $(3 \%, n=2)$, and increased stress/anxiety $(5 \%, n=3)$. The following negative outcomes for staff were also mentioned once: "decreased motivation for teaching," "inhibited the relationship or trust between students and staff," "challenges maintaining quality control of output," and "failed to achieve engagement from all students." 
Table 3 : Positive outcomes of partnership for students

\begin{tabular}{|c|c|c|}
\hline Positive Outcomes for Students & Percentage & Number \\
\hline Increased student engagement/motivation/ownership for learning & 56 & 37 \\
\hline Increased student confidence/self-efficacy & 45 & 29 \\
\hline $\begin{array}{l}\text { Increased understanding of the "other's" experience (e.g. students understanding } \\
\text { staff experiences) }\end{array}$ & 39 & 25 \\
\hline Enhanced relationship or trust between students and staff & 37 & 24 \\
\hline $\begin{array}{l}\text { Increased student learning about their own learning (meta-cognitive learning, } \\
\text { self-evaluation, self-awareness) }\end{array}$ & 35 & 23 \\
\hline $\begin{array}{l}\text { Raised awareness of graduate attributes or employability skills or career } \\
\text { development }\end{array}$ & 32 & 21 \\
\hline Increased sense of belonging to university or discipline or community & 31 & 20 \\
\hline Improved student content/discipline learning (actual or perceived) & 29 & 19 \\
\hline Positively shifted identity as student/learner/person/professional & 28 & 18 \\
\hline Enhanced student-student relationships & 22 & 14 \\
\hline Positively shifted traditional power dynamics between students and academics & 19 & 12 \\
\hline $\begin{array}{l}\text { Improved learning outside of discipline, including critical skill development not } \\
\text { linked directly to employability }\end{array}$ & 17 & 11 \\
\hline Engaged or empowered under-represented students & 9 & 6 \\
\hline Not stated & 8 & 5 \\
\hline Improved academic performance (as reported via assignment or grades) & 6 & 4 \\
\hline Networking and building critical relationships & 3 & 2 \\
\hline Publication and policy change & 3 & 2 \\
\hline Opportunity to pursue own research questions and development as researcher & 3 & 2 \\
\hline Insight into how research is conducted & 3 & 2 \\
\hline Other & 8 & 5 \\
\hline Total & & 285 \\
\hline
\end{tabular}


Table 4: Positive outcomes of partnership for staff

\begin{tabular}{|c|c|c|}
\hline Positive Outcomes for Staff & Percentage & Number \\
\hline Enhanced the relationship or trust between students and staff & 43 & 28 \\
\hline Development of new or better teaching or curriculum materials & 31 & 20 \\
\hline $\begin{array}{l}\text { Increased understanding of the "other's" experience (e.g. staff understanding } \\
\text { student experiences or vice versa) }\end{array}$ & 28 & 18 \\
\hline New beliefs about teaching and learning that change practices for the better & 23 & 15 \\
\hline Not stated & 22 & 14 \\
\hline Re-conceptualization of teaching as a collaborative process to foster learning & 19 & 12 \\
\hline Positively shifted traditional power dynamics between students and academics & 15 & 10 \\
\hline Positively shifted identity as student/learner/person/professional & 14 & 9 \\
\hline Increased motivation for teaching, research, and participation in partnerships & 9 & 6 \\
\hline Find teaching to be more enjoyable/rewarding & 9 & 6 \\
\hline Programmatic changes/changes to teaching & 6 & 4 \\
\hline Improved personal career prospects and networking & 5 & 3 \\
\hline Metacognition/knowledge and understanding of teaching and learning & 3 & 2 \\
\hline New research and publication & 3 & 2 \\
\hline Inspired by student partners & 3 & 2 \\
\hline Increased/improved communication & 3 & 2 \\
\hline Other & 5 & 3 \\
\hline Total & & 157 \\
\hline
\end{tabular}


Table 5 : Negative outcomes of partnerships for students

\begin{tabular}{|c|c|c|}
\hline Negative Outcomes & Percentage & Number \\
\hline $\begin{array}{l}\text { Inhibited the relationship or trust between students and staff (implying shift in } \\
\text { "power" relationships but don't say "power" or "hierarchy") }\end{array}$ & 6 & 4 \\
\hline Lack of improvement/lack of challenge in desired areas & 3 & 2 \\
\hline $\begin{array}{l}\text { Reinforced pre-existing power inequalities or hierarchical structures (terms } \\
\text { "power" or "hierarchy" explicitly used) }\end{array}$ & 3 & 2 \\
\hline Decreased student engagement/motivation/ ownership for learning & 3 & 2 \\
\hline Lack of one-on-one supervision & 2 & 1 \\
\hline Decreased student confidence/self-efficacy & 2 & 1 \\
\hline Decreased academic performance (as reported via assignment or grades) & 2 & 1 \\
\hline Reduced student-staff contact time & 2 & 1 \\
\hline Inhibited relationship between students and other students & 2 & 1 \\
\hline Negatively shifted "identity" as student/learner/person/professional & 2 & 1 \\
\hline Decreased sense of belonging to university or discipline or community & 2 & 1 \\
\hline Feeling isolated from peers after leaving course & 2 & 1 \\
\hline Frustration at slow pace of pedagogical change & 2 & 1 \\
\hline Larger time commitment than expected & 2 & 1 \\
\hline Not stated & 74 & 48 \\
\hline Total & & 69 \\
\hline
\end{tabular}

\section{LIMITATIONS}

It is important to acknowledge that the results reported here are specific to the body of empirical partnership literature that was defined by our selection process to create the initial database of works and the inclusion/exclusion criteria. The development of the database is biased toward works on partnership as identified by experts in the field. While it was necessary to establish clear criteria for a systematic literature review, we acknowledge that important research and discussion occurs outside of empirical studies, such as in purely theoretical articles, reflective essays, practice-based case studies, opinion pieces, and in those bodies of knowledge that reflect partnership but are not framed explicitly as SaP with associated terminology (e.g., subject-based research and inquiry). 


\section{DISCUSSION}

Four themes that cut across our results emerged from our analysis and interpretation of the data. We present and discuss these themes below aiming to respond to the broader question of how SaP is presented in the recent academic literature. We then propose nine implications to guide future practice and research.

\section{Reciprocity of partnership}

Cook-Sather and Felten (2017) discuss how an "ethic of reciprocity" enables partnership practices:

a process of balanced give-and-take not of commodities but rather of contributions: perspectives, insights, forms of participation. There is equity in what is exchanged and how it is exchanged; however, those who are involved in the exchange do not get and give exactly the same things.

Reciprocity in partnership is premised on dialogue, negotiation, and exchange of ideas between partners. This interaction positions both students and staff as having essential expertise to contribute to the goal of furthering education. Bird and Koirala (2002) described shared goals, risks, and learning as essential, while Healey et al. (2014) framed staff and students as co-learners. Partnership literature has also positioned students and staff as collaborators (Taylor \& Wilding, 2009) and colleagues (Matthews et al., in press). Reciprocity in partnership thus inherently subverts the traditional power hierarchy between learners and teachers by re-positioning partners as learners and teachers.

Our review explored how students and staff participate in co-authorship, and illuminated who gets to tell the empirical story of partnership in the literature. Interpreting these results through the lens of reciprocity in partnership, we found that reciprocity does not always translate into co-authorship. The fact that the majority of articles had a staff first author (88\%) with one-third listing a student co-author raises the question: To what extent are students and staff shaping the SaP body of literature together? Co-inquiry and co-authorship represent two important ways in which collaboration can exist within the context of partnership. Extending co-inquiry through to the writing process creates an opportunity for meaningful incorporation of student expertise and the positing of students as equals (Little, 2011). While our literature review captured a plethora of SaP practices premised on the ideals of reciprocity and shared responsibility, the artefacts (publications) of those interactions tended to be staff-centric. There are many explanations for why staff might be more likely to lead and co-author such works than students. In some instances, for example, the timeframe for the research and publication process may extend well beyond that of the partnership initiative that forms the focus of such reporting. In other instances, students may not have the time or interest in engaging in this process within the context of heavy university workloads or career aspirations outside of academia where publishing is of less value. These results nonetheless suggest that the reciprocity of partnership enacted in practice is not necessarily extending fully into research. This trend also raises the question: Are there new ways of 
thinking and new genres of writing that can transform how SaP research is conducted and reported that would encourage the extension of partnership through to publication?

The "ethic of reciprocity" lens also helps make sense of the way outcomes are reported about partnership, and where outcomes for both students and staff might be anticipated. Authors of the analyzed articles reported considerably more outcomes (both positive and negative) for students than for staff. This student-centric reporting of partnership may potentially reflect that SaP can be seen as a strategy to enhance the student experience, thereby prioritizing the student response. This does, however, potentially communicate a deficit mindset derived from a history of student engagement rhetoric, which implies that engagement, and by extension partnership, is something "done to" rather than "done with" students (Matthews, 2016). The combination of these results with those on authorship practices raises tensions around whether empirical literature has the tendency to conform to the traditional paradigm of staff-centric reporting on student-centric outcomes, rather than demonstrating a more reciprocal process of students and staff learning, inquiring, and reporting together.

\section{Making space for sharing the (equal) realities of partnership}

Reporting bias, whereby authors tend to report only positive results, has been acknowledged in higher education research (Dawson \& Dawson, 2016). Our results suggest similar bias in the emerging SaP literature where positive outcomes around partnerships dominate. It is important to recognize the realities and challenges that partnerships may face especially as partnerships or partnership programs are evolving (Marquis et al., 2016; Bovill et al., 2016; Allin, 2014). This recognition is particularly necessary insofar as some of the negative outcomes mentioned in the dataset (e.g., reinforcing power inequalities or inhibiting the development of trust) run counter to the avowed goals of partnership work. Attention to when and how partnership efforts might result in outcomes antithetical to their purposes seems essential to realizing the potential of such work, and conversely, to not overselling its positive aspects.

Dawson and Dawson (2016) proposed several reasons for reporting bias in higher education research: orientation to positive outcomes amongst funding bodies, blurred boundaries between SoTL and educational research, poor research design, or academics feeling pressure to produce. We also suggest that inequalities may exist in the focus of, or methods used by, publishing authors of our analyzed articles insofar as they may focus more predominantly on "what worked" for students. Conversely, students may feel a certain pressure, within the power dynamics of higher education, to report primarily positive outcomes and thus might not be critical of the staff who may be responsible for assessment. All these are possible explanations for the positively oriented trend of reporting in our SaP literature review results. There are, however, real dangers for SaP in withholding challenges and lessons learned from failures affecting those who want to establish partnerships. As one example, MercerMapstone, Dvorakova, Groenendijk, and Matthews (in press) articulate that "based on reading literature that tended to emphasize the positive outcomes of students as partners," both student and staff authors felt they needed to enact an idealized notion of partnership that was aspirational and left "no space for the nitty-gritty messiness and conflicts that are also an

Mercer-Mapstone, L., Dvorakova, L.S., Matthews, K.E., Abbot, S., Cheng, B., Felten, P., Knorr, K., 15 Marquis, E., Shammas, R., \& Swaim, K. (2017) A Systematic Literature Review of Students as Partners in Higher Education. International Journal for Students as Partners 1 (1) 
inherent part of the realities of genuine partnership." Ensuring that research focuses equally on the positive and negative aspects of both student and staff experiences will be important not only in ensuring early adopters go in with a strategy for facing such potential challenges - "eyes wide open" so to speak-but also in embracing the reciprocal nature of partnership itself.

\section{Engaging in partnership practices in higher education}

Our categorization of initiatives according to the Healey et al. (2014, Figure 1) model points toward significant trends within current empirical research. The prominence of curriculum design and pedagogic consultancy and, to a lesser extent, SoTL, suggests a much greater emphasis in recent literature on the "enhancement of learning and teaching" side of the model than on "learning, teaching, and research partnerships." These results run counter to the prevalence of higher education partnership practices indicated by Healey et al. (2014) who state, in the development of the model, that: "whereas most students in a programme may be engaged in learning and research, it is very rare that most students in a programme are engaged as partners in the enhancement of learning and teaching practice and policy, beyond giving their opinions or evaluations" (p23).

We can look to other results in the current study to help explain such a trend. Our findings suggest that the majority of articles analyzed focused on making sense of what partnership looks like outside of the curriculum where "enhancement of learning and teaching" activities tend to occur. Such activities outside of the curriculum also tend to include smaller numbers of students, as was the case in our results. This highlights, then, a trend in our review of practitioners engaging in partnerships that are small scale, extracurricular, and focused on teaching and learning enhancement. Perhaps this makes sense as such activities may be more appealing or manageable to those wishing to adopt and report on partnership practice. Another explanation might take into account the practical considerations or restrictions that exist within classrooms and the fact that power dynamics can play out particularly strongly in classrooms (Flint, 2016). Partnerships are relational by nature which also may contribute to this trend as relationships are more easily cultivated on a one-to-one or small-group basis.

The predominant focus on curriculum design and pedagogic consultancy, and SoTL may also point towards an explanation for the significant focus on partnerships at the undergraduate level where such activities are more likely to occur. This does, however, suggest that partnership practices at the postgraduate-student level is potentially an under-explored or under-reported arena worthy of future research.

The fact that most of the partnership activities described in the empirical literature happen outside of students' coursework supports the finding that comparatively less attention has been paid to the "learning, teaching, and research partnerships" side of the Healey et al. (2014) model. This side of the model tends to include larger numbers of students where issues of "scaling up" present challenges to SaP work.

This focus might also be explained by the fact that many practices in subject-based research and inquiry, and learning, teaching, and assessment are reported in research that does not employ a partnership lens. There is a large, distinct body of literature on undergraduate research and inquiry (e.g., Healey \& Jenkins, 2009), some of which takes up initiatives and ideas that overlap substantially with discussions of partnership (see Levy, 2011; Neary, 2014). 
Partnership itself, however, is less often considered within this literature (see, however, Little, 2011). Similarly, a substantial thread of assessment research is premised on dialogue and trust between students and educators (see Boud \& Molloy, 2013), and separately, literature on student-to-student learning relationships (see Newton \& Ender, 2010; Bryson, 2014) also resonates with partnership, yet neither bodies of literature use a partnership framework or language. It makes sense that established pedagogical research is not explicitly linked to SaP given that $\mathrm{SaP}$ is a newer language that encompasses many existing practices. Thus, future research that brings together these bodies of literature and considers points of congruence and discrepancy between them might generate significant insights (Marquis, 2016).

\section{Toward inclusive, partnered learning communities in higher education}

Healey et al. (2014) state that "embedding sustainable partnership beyond discrete projects and initiatives requires that working and learning in partnership becomes part of the culture and ethos of an institution" (p. 8). Matthews et al. (in press) argue that "the extent to which we value students and staff working collaboratively informs the transformative potential of partnership," which represents a "radical cultural shift" toward inclusive "egalitarian learning communities." Several universities internationally have drawn on this transformative aspiration of SaP to guide institutional strategies for teaching and learning or have integrated SaP significantly into university practice and culture (e.g., Bryn Mawr College, Haverford College, McMaster University, Plymouth University, University of Birmingham, University of Queensland, Ulster University, University of Winchester). This indicates a move toward largescale enactment of SaP practices by students and staff across disciplines in both the formal, assessed curriculum, and beyond in extra-curricular teaching enhancement and policy efforts.

The partnership initiatives described most frequently in our study, however, were predominantly isolated case-study examples of small-scale practices external to the assessed curriculum. Focusing on and enacting partnership more frequently at this level does risk taking an "elite" approach (Kuh, 2007) to partnership pedagogies which potentially prioritizes voices that are already privileged and engaged (Flint, 2016; Felten et al., 2013; Cook-Sather, 2015).

Hart (1992), in the context of school-level education, argued that opportunities to participate in one's own education must be made available to all students. This notion translates easily to the context of partnership in higher education particularly within the aim of building a learning community where students and staff are valued as partners. If we seek to understand how such cultural change occurs, then it is important to explore multiple practices that span disciplines within institutions and how those practices signal the manner in which students and staff are enacting SaP as members of partnered learning communities. Some (e.g., Macfarlane, 2016) have argued against "mainstreaming" and enforcing concepts like student engagement (and by extension, partnership), suggesting that this process does not account for students' different interests and preferences, and therefore divests them of their autonomy and agency as learners. It is arguable then that institutional SaP opportunities should be made available in ways that traverse both curricular and extra-curricular domains as it is difficult to imagine, for example, how a learning community of partnership in higher education might be built when the majority of practices are occurring outside of the classroom.

If such learning communities are to be as inclusive as possible, we might also look beyond numbers to how people are enabled to engage in partnership and with whom. Our

Mercer-Mapstone, L., Dvorakova, L.S., Matthews, K.E., Abbot, S., Cheng, B., Felten, P., Knorr, K., 17 Marquis, E., Shammas, R., \& Swaim, K. (2017) A Systematic Literature Review of Students as Partners in Higher Education. International Journal for Students as Partners 1 (1) 
results indicate that approximately one third of initiatives paid students for their involvement. This raises issues of equity among student cohorts, and between the students and the staff with whom they partner. Non-payment creates challenges for students who cannot afford to undertake unpaid partnership initiatives outside of the curriculum, privileging certain students for reasons that have nothing to do with the goals of a partnership. Similarly, if students are not being compensated for work that paid staff typically would complete, serious questions about equity and reciprocity can arise. These results echo Bovill et al. (2016) in suggesting that concrete strategies for considering questions of inclusion and equity in partnership initiatives are required.

Our findings also indicate that students were positioned as partnering with academics/faculty/teaching staff/tutors more than other roles. This reflects the common understanding of "partnership" in the literature that positions partnership as a collaboration between academics and students. Interestingly, we found that the second most common partnership structure was that of student-student partnership-troubling the predominant rhetoric of "student-staff partnership" or literal interpretations of SaP. This does, however, revision a broader view of a partnered learning communities and points towards the need for deeper consideration around the language of SaP. This also suggests there is space to tease apart some of the complexity and nuance around inclusivity in partnership as to who is engaged and included in partnership learning communities.

\section{Implications for future partnership research and practice}

We have presented and discussed the results of a systematic literature review on students as partners in higher education. This evidential baseline has many implications that we highlight here in the hopes of guiding future research and practice.

1. We found low numbers of inter-institutional or cross-disciplinary initiatives and studies. Future research illuminating how partnerships translate across disciplines, institutions, countries, and cultures would be valuable in pointing towards which facets of partnership might be context-specific and which might be more generalizable.

2. Authorship of publications was staff-centric with low rates of staff-student coauthorship. Exploring how and why students and staff do or do not extend coinquiry into co-authorship would be useful in elucidating mechanisms to create space and practices for students to shape partnership research alongside staff. At times, practitioners may default to the normative hierarchical university paradigm when reporting and publishing on SaP, naming staff as authors and obscuring the roles of student partners in this work.

3. The outcomes of partnership were reported with a student-centric focus. This suggests a potential need for further research on outcomes for staff aligning with the notion of reciprocity and equal benefit to both student and staff partners that is central to partnership (Cook-Sather et al., 2014).

4. A focus on reporting positively-oriented outcomes was observed across the literature. We encourage practitioners to enter into the brave spaces of partnership 
(Aroa \& Clemens, 2013; Cook-Sather, 2016) by exploring and sharing in more detail the challenges and negative outcomes of partnerships that would help to complete the narrative around these complex relationships.

5. The categorization of initiatives according to the Healey et al. (2014) model was weighted significantly toward partnership activities that focus on the enhancement of teaching and learning. Teasing apart reasons behind where, how, and why practitioners choose certain partnership practices in light of these findings would be of great value. Furthermore, exploring through a partnership lens bodies of literature such as subject-based research and inquiry, student-student learning, and teaching, learning and assessment not explicitly framed as SaP-but which have values that resonate with partnership-would expand thinking across these bodies of work.

6. Scaling up partnership initiatives and making opportunities accessible to the majority rather than a select few are frequently raised tensions in this arena and were prevalent in our results. The question of whether and how partnership initiatives might be expanded will be integral to the endeavor of creating learning communities which foster a culture of partnership, allowing more sustainable practices in the long term.

7. Partnership initiatives were predominantly framed as occurring between students and academic staff. Further exploration of where and how partnerships are occurring among, for example, students and other students (with a particular sparsity of research on postgraduate students), students and professional staff, or students and stakeholders external to universities, would move toward a more inclusive understanding of partnership.

8. A large number of the papers analyzed lacked sufficient detail to be categorized within our analysis framework. Future research might focus on describing the context of SaP initiatives and their institutional settings more fully in order to help others adopt the range of innovative practices shared across the literature.

9. There was a predominant focus on outcomes for individuals immediately involved in partnerships. While logical, further consideration of if and how partnership is working to transform institutional cultures more broadly would help to shore up (or complicate) claims about its radical potential (Matthews et al., in press).

\section{CONCLUSION}

Our intention in conducting this systematic literature review was to explore the empirical research to understand what the research on partnership communicates across the literature in an effort to support the translation of partnership research into practice. We have highlighted four cross-cutting themes that emerged from our results: reciprocity; realities of partnership outcomes; context of practices; and inclusive, partnered learning communities. Drawing on these themes, we proposed nine implications to guide future research and practice. These results, trends, and implications highlight the fact that SaP as a theory, an ethos, and a practice is as complex, nuanced, and multifaceted as the educational institutions within which partnerships unfold. Through the examination of practices reported in literature that spans

Mercer-Mapstone, L., Dvorakova, L.S., Matthews, K.E., Abbot, S., Cheng, B., Felten, P., Knorr, K., 19 Marquis, E., Shammas, R., \& Swaim, K. (2017) A Systematic Literature Review of Students as Partners in Higher Education. International Journal for Students as Partners 1 (1) 
institutions, countries, and contexts, we hope to illuminate new avenues for SaP research by establishing an evidential baseline for inquiry into SaP, and to propel the field into new and fruitful directions that enrich teaching and learning in higher education.

\section{ACKNOWLEDGEMENTS}

We would like to acknowledge the significant work of the rest of our analysis team in contributing to the piloting and development of the analysis instrument, and the data collection process: Thanks to Anita Acai, Christine Black, Alison Cook-Sather, Mick Healey, Ruth Healey, Gali Katznelson, Sabrina Kirby, Alex Lerczak, Mythili Nair, and Jarred Turner.

\section{NOTES ON CONTRIBUTORS}

Sophia Abbot is a Fellow for Collaborative Programs at the Collaborative for Learning and Teaching at Trinity University, United States.

Breagh Cheng is a recent graduate of the Honors Bachelor of Science Program at McMaster University, Canada.

Lucie S. Dvorakova is an honors student with the Institute for Molecular Bioscience and a summer scholar at the Institute for Teaching and Learning Innovation at the University of Queensland, Australia.

Peter Felten is Assistant Provost for Teaching and Learning, Executive Director of the Center for Engaged Learning, and Professor of history at Elon University, United States.

Kris Knorr is the Program Area Lead for Educational Development at McMaster's MacPherson Institute for Leadership, Innovation, and Excellence in Teaching, Canada.

Elizabeth Marquis is an Assistant Professor in the Arts \& Science program at McMaster University and Associate Director (Research) of the University's MacPherson Institute for Leadership, Innovation, and Excellence in Teaching, Canada.

Kelly E. Matthews is a Senior Lecturer at the University of Queensland, Australia.

Lucy Mercer-Mapstone is a PhD student in the Sustainable Minerals Institute and a co-fellow in the Institute for Teaching and Learning Innovation at the University of Queensland, Australia.

Rafaella Shammas is an honors Arts and Science and Biochemistry student at McMaster University, Canada.

Kelly Swaim is an honors student of history education at Elon University, United States. 


\section{REFERENCES}

Allin, L. (2015). Collaboration between staff and students in the scholarship of teaching and learning: The potential and the problems. Teaching \& Learning Inquiry, 2(1), 95-102. Retrieved from http://dx.doi.org/10.20343/teachlearninqu.2.1.95

Amundsen, C., \& Wilson, M. (2012). Are we asking the right questions? A conceptual review of the educational development literature in higher education. Review of Educational Research, 82(1), 90-126. doi:10.3102/0034654312438409

Aroa, B., \& Clemens, K. (2013). From safe spaces to brave spaces: a new way to frame dialogue around diversity and social justice. In L. Landreman (Ed.), The art of effective facilitation (pp. 135-150). Sterling, VA: Stylus.

Bird, C., \& Koirala, B. (2002). Partnership in education: A review of modalities and their potential application in service delivery within the government primary education sector. Kathmandu: European Commission Basic Primary Education Project.

Boud, D., \& Molloy, E. (2013). Rethinking models of feedback for learning: The challenge of design. Assessment \& Evaluation in Higher Education, 38(6), 698-712. Retrieved from http://dx.doi.org/10.1080/02602938.2012.691462

Bovill, C., Aitken, G., Hutchison, J., Morrison, F., Roseweir, K., Scott, A., \& Sotannde, S. (2010). Experiences of learning through collaborative evaluation from a postgraduate certificate in professional education. International Journal for Academic Development, 15(2), 143154. Retrieved from http://dx.doi.org/10.1080/13601441003738343

Bovill, C., Cook-Sather, A., Felten, P. (2011). Students as co-creators of teaching approaches, course design, and curricula: Implications for academic developers. International Journal for Academic Development, 16(2), 133-145. Retrieved from http://dx.doi.org/10.1080/1360144X.2011.568690

Bovill, C., \& Felten, P. (2016). Cultivating student-staff partnerships through research and practice. International Journal for Academic Development, 21(1), 1-3. doi:10.1080/1360144X.2016.1124965

Bovill, C., Cook-Sather, A., Felten, P., Millard, L., \& Moore-Cherry, N. (2016). Addressing potential challenges in co-creating learning and teaching: Overcoming resistance, navigating institutional norms and ensuring inclusivity in student-staff partnerships. Higher Education, 71, 195-208. doi:10.1007/s10734-015-9896-4

Bryson, C. (Ed.) (2014). Understanding and developing student engagement. New York: Routledge.

Cook-Sather, A. (2014). Student-faculty partnership in explorations of pedagogical practice: A threshold concept in academic development. International Journal for Academic Development, 19(3), 186-198. Retrieved from http://dx.doi.org/10.1080/1360144X.2013.805694

Cook-Sather, A. (2015). Dialogue across differences of position, perspective, and identity: Reflective practice in/on a student-faculty pedagogical partnership program. Teachers College Record, 117(2), 1-42. Retrieved from http://repository.brynmawr.edu/edu pubs/32/ 
Cook-Sather, A. (2016). Creating brave spaces within and through student-faculty pedagogical partnerships. Teaching and Learning Together in Higher Education, 18. Retrieved from http://repository.brynmawr.edu/tlthe/vol1/iss18/1

Cook-Sather, A., \& Abbot, S. (2016). Translating partnerships: How faculty-student collaboration in explorations of teaching and learning can transform perceptions, terms, and selves. Teaching \& Learning Inquiry, 4(2), 1-14. Retrieved from http://dx.doi.org/10.20343/10.20343/teachlearninqu.4.2.5

Cook-Sather, A., \& Agu, P. (2013). Students of color and faculty members working together toward culturally sustaining pedagogy. To Improve the Academy, 32, 271-285.

Cook-Sather, A., Bovill, C., \& Felten, P. (2014). Engaging students as partners in learning and teaching: A guide for faculty. San Francisco, CA: Josey-Bass.

Cook-Sather, A. \& Felten, P. (2017). Ethics of academic leadership: Guiding learning and teaching. In F. Su \& M. Wood (Eds.), Cosmopolitan perspectives on academic leadership in higher education (pp. 175-191). London: Bloomsbury.

Dawson, P., \& Dawson, S. L. (2016). Sharing successes and hiding failures: "Reporting bias" in learning and teaching research. Studies in Higher Education, 1-12. doi:10.1080/03075079.2016.1258052

Felten, P., Bagg, J., Bumbry, M., Hill, J., Hornsby, K., Pratt, M., \& Weller, S. (2013). A call for expanding inclusive student engagement in SoTL. Teaching and Learning Inquiry, 1(2), 63-74. Retrieved from http://dx.doi.org/10.20343/teachlearninqu.1.2.63

Flint, A. (2016). Moving from the fringe to the mainstream: opportunities for embedding student engagement through partnership. Student Engagement in Higher Education Journal, 1(1), 1-6. Retrieved from https://journals.gre.ac.uk/index.php/raise/article/view/382/340

Hart, R. A. (1992). Children's participation: From tokenism to citizenship. Innocenti Essay, 4, 138. Retrieved from https://www.unicef-irc.org/publications/100/

Healey, M. (2016) Students as partners and change agents: A selected bibliography. Retrieved from: www.mickhealey.co.uk/resources

Healey, M., Flint, A., \& Harrington, K. (2014). Engagement through partnership: Students as partners in learning and teaching in higher education. York: Higher Education Academy. Retrieved from https://www.heacademy.ac.uk/engagement-through partnership-students-partners-learning-and-teaching-higher-education

Healey, M., \& Jenkins, A. (2009). Developing Undergraduate Research and Inquiry. York: Higher Education Academy. Retrieved from https://www.heacademy.ac.uk/resource/developingundergraduate-research-and-inquiry

Kennedy, M. M. (2007). Defining a literature. Educational Researcher, 36(3), 139-147. https://doi.org/10.3102/0013189X07299197

Kuh, G. (2007, June 15). How to help students achieve. Chronicle of Higher Education, 53(41), B12-B14. Retrieved from http://www.chronicle.com/article/How-to-Help-Students Achieve/31980/

Levy, P. (2011). Embedding inquiry and research into mainstream higher education: A UK perspective. CUR Quarterly, 32(1), 36-42. Retrieved from http://www.cur.org/publications/curquarterly/ 
Little, S. (Ed.) (2011). Staff-student partnerships in higher education. London: Continuum.

Macfarlane, B. (2016). The performative turn in the assessment of student learning: A rights perspective. Teaching in Higher Education, 21(7), 839-853. Retrieved from http://dx.doi.org/10.1080/13562517.2016.1183623

Marquis, E., Puri, V., Wan, S., Ahmad, A., Goff, L., Knorr, K., Vassileva, I., \& Woo, J. (2016). Navigating the threshold of student-staff partnerships: A case study from an Ontario teaching and learning institute. International Journal for Academic Development, 21(1), 4-15. doi: 10.1080/1360144X.2015.1113538

Marquis, E. (2016 unpublished manuscript). Undergraduate research and student-staff partnerships: Supporting the development of student scholars at a Canadian teaching \& learning institute. McMaster University. Manuscript in preparation.

Matthews, K. E. (2016). Students as partners as the future of student engagement. Student Engagement in Higher Education Journal, 1(1) 1-5. Retrieved from https://journals.gre.ac.uk/index.php/raise

Matthews, K.E., Cook-Sather, A., \& Healey, M. (in press). Connecting learning, teaching, and research through student-staff partnerships: Toward universities as egalitarian learning communities. In V. Tong, A. Standen, \& M. Sotiriou (Eds.), Research equals teaching: Inspiring research-based education through student-staff partnerships. London: UCL Press.

Matthews, K. E., Divan, A., John-Thomas, N., Lopes, V., Ludwig, L. O., Martini, T. S., Motley, P. \& Tomljenovic-Berube, A. M. (2013). SoTL and students' experiences of their degree-level programs: An empirical investigation. Teaching \& Learning Inquiry, 1(2), 75-89. doi:10.1353/iss.2013.0020

Mercer-Mapstone, L., Dvorakova, S. L., Groenendijk, L., \& Matthews, K. E. (in press). Idealism, conflict, leadership, and labels: Reflections on co-facilitation as partnership practice. Teaching and Learning Together in Higher Education.

Neary, M. (2014). Student as producer: Research-engaged teaching frames university-wide curriculum development. CUR Quarterly, 35(2), 28-34.

Newton, F., \& Ender, S. (2010). Students helping students: A guide for peer educators on college campuses. San Francisco: Jossey-Bass.

Plymouth University (2016). Students as partners. Retrieved from https://www.plymouth.ac.uk/student-life/students-as-partners

Taylor, P., \& Wilding, D. (2009). Rethinking the values of higher education: The student as collaborator and producer? Undergraduate research as a case study. Gloucester, England: Quality Assurance Agency for Higher Education.

The University of Queensland (2016). Student Strategy 2016-2020 White Paper. Retrieved from https://student-strategy.uq.edu.au/files/453/Student-Strategy WhitePaper.pdf

Werder, C., \& Otis, M., (Eds.). (2010). Engaging student voices in the study of teaching and learning. Sterling, VA: Stylus.

Werder, C., Thibou, S., \& Kaufer, B. (2012). Students as co-inquirers: A requisite theory in educational development. Journal of Faculty Development, 26(3), 34-38. 